\title{
A Development Area of surplus reserve production ratio influence
}

\author{
factors \\ Yakun Liu \\ Exploitation and Development Research Institute, Daqing Oilfield Company Ltd, \\ Daqing,163412,China
}

\begin{abstract}
Keywords: Recoverable Reserves; Reserve Production ratio; Oil Recovery Rate; Calibration of The Recoverable Reserves.
\end{abstract}

\begin{abstract}
The remaining oil reserve production ratio of A Development Area is low,there is a serious contradiction between the remaining recoverable reserves and stable production.Aiming at the analysis of the low remaining oil reserve production ratio of the $A$ Development Area,quantifying parts of the influence factors which influence the recoverable reserves value and re-accounting the remaining recoverable reserves.It is very necessary to guide the compiling of the "13th Five-Year" plan of the A Development Area .The results show that: the number of drilling wells in water flooding production block,the strength of comprehensive adjustment can influence the annual recoverable reserves value added; The scale of geological reserves of tertiary oil recovery block has certain effect on the year recoverable reserves value added;the value of EOR of tertiary oil recovery block which had been put into operation has great influence on the calibrated recoverable reserves; The recognition and calibration of sporadically distributed wells and test blocks which have not calibrated recoverable reserves, which will provide contribution to the increase value of recoverable reserves. The research results also provide new ideas for the development blocks of low remaining oil reserve production ratio in Daqing Oilfield.
\end{abstract}

\section{Introduction}

At present, most domestic oilfields have entered the development stage of super high water cut and high recovery degree, the water flooding development of old oilfield is still the main research subject of oilfield development and further enhanced oil recovery[1-3]. Water flooding and polymer flooding coexist with multi production well patterns in the current A development area after 40-year large-scale development adjustment, in which underground injection-production relationship is very complex.By the end of 2014, the geological reserves of A Development Area were $61290 * 104 t$, recoverable reserves were $28097 * 104 \mathrm{t}$, the remaining recoverable reserves were $1797 * 104 \mathrm{t}$, the remaining oil recovery rate of recoverable reserves was $19.63 \%$, according to the "13th Five-Year" planning research results of A Development Area , by 2020, the only remaining recoverable reserves of A Development Area will be $35 * 104 t$, the high degree of reserve recovery of recovery reserves will reach up to $99.88 \%$.From the viewpoint of the remaining oil reserve production ratio and the remaining oil recovery rate of recoverable reserves, stable situation of oil field is grim. Need to re- calibrate the recoverable reserves of A Development Area ,verify the remaining recoverable reserves, implement resource potential that can be used for exploitation,which can better guide the development planning. For the above reasons, the author started from the influence factors of recoverable reserves, such as water flooding, polymer flooding, test blocks ,based on thorough analysis of various influence factors ,quantified part of influence factors of the recoverable reserves, verified the reliability of quantitative results ,confirmed the remaining recoverable 
reserves potential that can be used for exploitation of A Development Area,offered a significant guide for the later development modification of oilfield[4-6].

\section{Reasons for low recoverable reserves}

1.The Number of New Water Flooding Wells Decreased Year by Year, and There is No New Comprehensive Adjustment Reserves. From the development process of the A Development Zone, It has experienced a encryption, second encryption, expansion of the edge, polymer flooding the four stages, the current water flooding, polymer flooding, the coexistence of the two mining methods[7-8]. From the number of years of drilling, the development object became worse gradually drilling potential gradually decreases, resulting in the number of new drilling decreased year by year, "11th Five-Year", only the injection production system adjustment, SA 0 group test, layer recombination a small amount of new drilling wells, The drilling number during "fifteen" is 205 every year , during"11th Five-Year" declined to 60 every year , the water flooding is the new recoverable reserves declined from an average of $160 * 104 \mathrm{t}$ to an average of $40 * 104 \mathrm{t}$, with an average annual increase of recoverable reserves dropped sharply; from the comprehensive adjustment, 1990-2004 water flooding comprehensive adjustment efforts in the year 500, an average annual increase of recoverable reserves of $130 * 104$ t with water content increasing, comprehensive adjustment potential has become smaller, since 2005, every year has no water flooding comprehensive adjustment increase recoverable reserves. The above two reasons have led to significant reduction in water flooding new recoverable reserves than the "fifteen" period.

2. The Polymer Flooding Block Has Been Improved to Enhance The Recovery Value and Increase The Recoverable Reserves. Calibrated polymer flooding blocks refers to the blocks which has entered the stage of water cut increasing and subsequent water flooding blocks. by the end of 2014, there were total 12 blocks in Saertu development zone. the blocks calibrating recoverable reserves, in accordance with the new block, applied to methods that geological reserves multiplied the value of improving recovery factor[9-11] . Recoverable reserves of new blocks were calibrated enough once. According to this method of calibrating recoverable reserves, in the reservoir blocks which were developed early, calibration value of improving recovery factor was only $12 \%$. While from a practical perspective, for class I oil reservoir blocks which had been transferred to subsequent water flooding development ,the value of improving recovery factor should be $17 \%$ - $18 \%$. So further calculation was needed .recoverable reserves of the 12 tertiary oil recovery blocks can be added $328.3 * 104 t$ on the basis of the original calibration of recoverable reserves. 
TABLE 1 Calibration table of recoverable reserves in polymer flooding block

\begin{tabular}{|c|c|c|c|c|c|c|c|}
\hline Block & $\begin{array}{c}\text { Reserves } \\
110^{4} \mathrm{t}\end{array}$ & $\begin{array}{c}\text { Polymer } \\
\text { Injection } \\
\text { Time }\end{array}$ & $\begin{array}{c}\text { Stop } \\
\text { Polymer } \\
\text { Injection } \\
\text { Time }\end{array}$ & $\begin{array}{r}\text { Improv } \\
\text { Polyn }\end{array}$ & $\begin{array}{l}\text { Recovery of } \\
\text { looding \% }\end{array}$ & $\begin{array}{c}\text { Calibration } \\
\text { Value of } \\
\text { Improve } \\
\text { Recovery } \\
\text { Factor /\% }\end{array}$ & $\begin{array}{c}\text { Difference } \\
\text { From } \\
\text { Calibration } \\
\text { Value of } \\
\text { Improve } \\
\text { Recovery } \\
\text { Factor } / 10^{4} \mathrm{t}\end{array}$ \\
\hline 1 & 1575 & 199512 & 200306 & 12.0 & 17.5 & 12.04 & 86.0 \\
\hline 2 & 1237 & 199608 & 200305 & 12.1 & 12.1 & 12.10 & 0.0 \\
\hline 3 & 752 & 199911 & 200606 & 11.5 & 12.1 & 11.48 & 4.7 \\
\hline 4 & 1367 & 199808 & 200508 & 11.2 & 17.8 & 11.24 & 89.7 \\
\hline 5 & 762 & 200105 & 201107 & 10.6 & 19.6 & 11.71 & 60.1 \\
\hline 6 & 837 & 200212 & 201107 & 14.1 & 14.7 & 14.05 & 5.4 \\
\hline 7 & 1452 & 200308 & & 9.8 & 9.8 & 9.8 & 0.0 \\
\hline 8 & 1062 & 200707 & & 9.5 & 9.5 & 9.5 & 0.0 \\
\hline 9 & 1296 & 200610 & & 8.3 & 13.0 & 10.33 & 34.6 \\
\hline 10 & 1314 & 200811 & & 8.1 & 14.5 & 12.92 & 20.8 \\
\hline 11 & 549 & 200910 & & 8.4 & 12.0 & 10.33 & 9.2 \\
\hline 12 & 584 & 201109 & & 8.1 & 13.0 & 9.93 & 17.9 \\
\hline Total & 12787 & & & & & & 328.3 \\
\hline
\end{tabular}

3. Other Newly Added Recoverable Reserves. According to the calibration of recoverable reserves, In the past five years, the test blocks and scattered wells that have been put into development have not been verified by the recoverable reserves. Polymer flooding test block including A block, which belongs to the first grade oil and weak base ASP flooding, block B, it belongs to the second grade oil and weak base ASP flooding, and block C, it belongs to weak base ASP flooding. The geological reserves of these three blocks are $878.3 * 10^{4} \mathrm{t}$, The recoverable reserves can be calculated according to the predicted recovery values after the end text of each block , the three test blocks are expected to increase recoverable reserves of $170.9 * 10^{4} \mathrm{t}$, In addition, the water flooding block D layer recombination zone and the Western pure oil fill it after drilling, combined with seismic injection production system adjustment, developped in 2009-2013. Total drilling 178 , is expected to increase recoverable reserves of $98.1 * 10^{4} \mathrm{t}$. Test wells and scattered production wells can increase the total recoverable reserves of $269.1 * 10^{4} \mathrm{t}$.

TABLE2 Table of enhanced oil recovery

\begin{tabular}{|c|c|c|c|c|c|}
\hline project & BLOCK & $\begin{array}{c}\text { Geological } \\
\text { Reserves } / 10^{4} \mathrm{t}\end{array}$ & $\begin{array}{c}\text { Polymer Flooding } \\
\text { Enhanced Oil } \\
\text { Recovery/\% }\end{array}$ & $\begin{array}{c}\text { Increase } \\
\text { Recoverable } \\
\text { Reserves } / 10^{4} \mathrm{t}\end{array}$ & Remarks \\
\hline & B & 116.3 & 28.0 & 32.6 & \\
\hline test & A & 549.0 & 18.2 & 100.0 & \\
\hline \multirow[t]{2}{*}{ block } & C & 213.0 & 18.0 & 38.3 & \\
\hline & $\mathrm{D}$ & & & 18.6 & No \\
\hline $\begin{array}{c}\text { Injection } \\
\text { production system } \\
\text { adjustment }\end{array}$ & $\mathrm{E}$ & & & 79.5 & Calibration \\
\hline Total & & 878.3 & & 269.1 & \\
\hline
\end{tabular}


The untabulated reservoirs of the water flooding has a certain thickness of the thickness of each layer in the A Development Zone, From the point of view of the use of water, from the use of water absorption data, the untabulated reservoirs water absorption ratio was $41 \%$, the proportion of the use was 45.4\%.According to the geological reserves of Institute report in 2006 of the A Development Area, the first class of independent geological reserves was $5223.05^{*} 10^{4} \mathrm{t}$, the first kind of gradual change of geological reserves was $315.85^{*} 10^{4} \mathrm{t}$, the first class of out balance sheet geological reserves was $5538.9 * 10^{4} \mathrm{t}$. According to the calculation of the final recovery rate of $30 \%$ of the outer geological reserves of this part, the outer layer can increase the recoverable reserves by $1661.67 * 10^{4} \mathrm{t}$.

\section{Recoverable reserves verification results}

Through the analysis, we found out the reasons for low remaining reserve-production ratio of A development area and recalculated the recoverable reserves. An additional $2259 * 10^{4}$ t were added in A Development Area of recoverable reserves after recalculation. By the end of 2014 ,the recoverable reserves of A Development Area was $30356 * 10^{4} \mathrm{t}$, the recovery ratio was $45.42 \%$. Using Tong's chart method to calibrate the A Development Area ,the recovery rate is $45.8 \%$ at the end of 2014 .The project "recoverable reserves evaluation" resulted the recovery rate is $46.45 \%$. Through comparison of different results, we further verify the reliability of the results.

According to the current plan, at the end of the "12th Five-Year" in A Development Area, the remaining recoverable reserves was $3507 * 10^{4} \mathrm{t}$, the remaining reserve production ratio was 9.49, the remaining oil recovery rate of recoverable reserves was $10.54 \%$. According to preliminary production plan in "13th Five-Year ",to 2020 the remaining recoverable reserves of A development area would be $2294 * 10^{4}$ t, the recovery degree of recoverable reserves would be $92.77 \%$. The recoverable reserves verification results will effectively guide the "13th Five-Year" development planning of A Development Area .

\section{Conclusions}

(1)To study the cause of low reserve-product ratio, we need analyze the following aspects: the amount of wells in water-flooding productive blocks,measures of comprehensive adjustments, the geological reserves of tertiary oil recovery areas which are already starting production, EOR in tertiary oil recovery areas which are already starting injecting chemicals.

(2)Recalculated the recoverable reserves in A Development Area, studied the potential of recoverable reserves, guiding the compiling of development plan in A Development Area during the "13th Five Years" , base on studying the influencing factors of the recoverable reserves in A Development Area.

(3) Analyzing the mechanism of lower recoverable reserves in A Development Area, which can be a reference to other similar areas in Daqing Oil Field.

\section{Acknowledgments}

Author introduction: Yakun Liu (1984-), male, Heilongjiang Zhaodong, bachelor degree, work in Exploitation and Development Research Instituteof Oilfield Company Ltd, Address: Heilongjiang Province, Daqing city ,exploitation and Development Research Instituteof Oilfield Company Ltd, Development Planning Research Laboratory. Zip code: 163712; Tel: (0459) 5508731; 13614596621; 


\section{References}

[1] Qiuyu Wang.Foreign high water bearing sandstone oil improving water flooding recovery technology progress [J].LithologicReservoirs,2012,24(3):123-128.

[2]Yajing Wang,Guo Shaobin.The application of grey system theory in evaluation of northern Songliao

Basin of Putaohua oil reservoir [J].Lithologic Reservoirs,2011，23（5） : 60-63.

[3]Yingzhi Zhang. The research trend of layers and well pattern evolution in high water cut stage in North Saertu Development Area [J]. Petroleum Geology \& Oilfield Development in Daqing,2006,25 (8),4-6.

[4] Xu Jianjun, Xu Yan-chao, Yan, Li-me,et.al. Research on the method of optimal PMU placement. International Journal of Online Engineering,v9, S7, p24-29, 2013

[5] Xu Jian-Jun, Y. Y. Zi., Numerical Modeling for Enhancement of Oil Recovery via Direct Current. International Journal of Applied Mathematics and Statistics，2013，43 (13) : 318-326

[6] Longchao, Zhu Jianjun, Xu; Limei, Yan. Research on congestion elimination method of circuit overload and transmission congestion in the internet of things. Multimedia Tools and Applications, p 1-20, June 27, 2016

[7] Yan Limei, Zhu Yusong, Xu Jianjun,et.al. Transmission Lines Modeling Method Based on Fractional Order Calculus Theory. TRANSACTIONS OF CHINA ELECTROTECHNICAL SOCIETY, 2014 ,Vol.29,No. 9:260-268 (In Chinese)

[8] YAN Li-mei, CUI Jia, XU Jian-jun,et.al. Power system state estimation of quadrature Kalman filter based on PMU/SCADA measurements. Electric Machines and Control. 2014, Vol.18 No.6,: 78-84. (In Chinese)

[9]YAN Limei,XIE Yibing, XU Jianjun, et.al. Improved Forward and Backward Substitution in Calculation of Power Distribution Network with Distributed Generation. JOURNAL OF XI'AN JIAOTONG UNIVERSITY,2013, Vol.47, No.6, p117-123. (In Chinese)

[10] Xu J.J., Gai D., Yan L.M. A NEW FAULT IDENTIFICATION AND DIAGNOSIS ON PUMP VALVES OF MEDICAL RECIPROCATING PUMPS. Basic \& Clinical Pharmacology \& Toxicology, 2016,118 (Suppl. 1), 38-38

[11] Changhao Geng,. Tong's chart in the application and revision of the prediction of oil recovery

[J]. China Petroleum and Chemical Standard and Quality 2007, 8 (2) : 233-235. 